\title{
Maximum Oxygen Uptake Capacity of Smokers of Different Age Groups
}

\author{
Satipati ChatterJeE, Swapan Kumar Dey, \\ and Samir Kumar NAG \\ Exercise Sports and Cardiorespiratory Physiology Laboratory, \\ Department of Physiology, University College of Science \\ and Technology, 92, Acharya Prafulla Chandra \\ Road, Calcutta 700009, India
}

\begin{abstract}
Eighty-four healthy asymptomatic sedentary smokers and 92 healthy sedentary non-smokers of the age range 20-59 years were investigated for their maximum oxygen uptake capacity $\left(\dot{V}_{\mathrm{O}_{2} \max }\right)$ and related cardiorespiratory parameters at the level of maximal exercise by bicycle ergometry. The subjects were blocked into four age decades of $20-29,30-39,40-49$, and 50-59 years to show the effect of smoking on $\dot{V}_{\mathrm{O}_{2} \max }$ of smokes of different age groups. The physical characteristics of smokers and non-smokers of comparable age groups did not show any significant difference. The smokers of each subsequent age group consumed $5.9 \pm 4.1,6.3 \pm 5.7,12.7 \pm 7.1$, and $11.5 \pm 9.1$ pack years of cigarettes, respectively (pack year $=$ number of packets of cigarettes per day $\times$ number of years of smoking). $\dot{V}_{\mathrm{O}_{2} \max }$ of smokers $(38.9 \pm 4.6$ $\left.\mathrm{ml} \cdot \mathrm{kg}^{-1} \cdot \min ^{-1}\right)$ was significantly lower $(p<0.05)$ than that of nonsmokers $\left(42.1 \pm 3.2 \mathrm{ml} \cdot \mathrm{kg}^{-1} \cdot \mathrm{min}^{-1}\right)$ only in the young age group of 20-29 years. $\dot{V}_{\mathrm{O}_{2} \max }$ expressed in per $\mathrm{kg}$ of the body weight $\left(\dot{V}_{\mathrm{O}_{2} \max } / \mathrm{BW}\right)$ was found to be significantly $(p<0.01)$ and negatively correlated with number of cigarettes smoked per day $(-0.36, p<0.01)$, number of years through which smoked $(-0.38, p<0.01)$, and pack years $(-0.42, p<0.01)$. In other age groups, though non-smokers predominated over smokers in $\dot{V}_{\mathrm{O}_{2} \max }$, the differences were not statistically significant. Also, in these age groups, smoking histories failed to reveal any significant correlation with $\dot{V}_{\mathrm{O}_{2} \max }$. This suggests that smoking impairs $\dot{V}_{\mathrm{O}_{2} \max }$ only in the young ages. By increasing age, $\dot{V}_{\mathrm{O}_{2} \max }$ was diminished by $13 \%$ from 20 to 59 years in non-smokers and $15.5 \%$ from 20 to 59 years in smokers. Age also diminished $\mathrm{HR}_{\max }$ and $\dot{V}_{\mathrm{E} \max }$ of smokers in the same manner as in the case of non-smokers. The $\dot{V}_{\mathrm{O}_{2} \max }$ of Indian sedentary non-smokers was found to be lower than those of Caucasians, Kurds, Yemenites, Europeans, and Africans. Values reported on Asians were found to be comparable with those of the present study.
\end{abstract}

Received for publication March 9, 1987 
Key words: maximum oxygen uptake, smoking, maximum heart rate, maximum pulmonary ventilation, aging.

The possible harmful effects of cigarette smoking have been consistently reported over the past three decades. CHEvalier et al. (1963), LARSEN (1963), MARTT (1963), and TAYLOR (1959) are just a few of the investigators who have made contributions in this area. Recent concern over cigarette smoking has resulted in the required addition of a warning label on all packs of cigarettes which states that "cigarette smoking is injurious to health or may be hazardous to your health."

Many of the early effects of smoking might be expected to cause some abnormality in oxygen exchange and transport (MARTT, 1963; ANTHONISEN et al., 1968; WALTER and NANCY, 1983) and thus affecting oxygen uptake capacity. Although oxygen uptake in the smokers may remain normal during rest and moderate activity, it is likely impaired during severe exertion.

Studies on maximum oxygen uptake capacity $\left(\dot{V}_{\mathrm{O}_{2} \max }\right)$ of normal sedentary Indian subjects of a wide age range are not available. All the studies so far reported were made on active subjects of the young age group except that of SENGUPTA et al. (1974), who reported maximum oxygen uptake capacity of active subjects of the age range 21-56 years. Other studies were based on young sedentary active subjects (BANERJEe et al., 1974; WALTER and NANCY, 1983).

The present study was, therefore, undertaken to determine: i) whether or not smoking has significant effect on maximum oxygen uptake capacity of different age groups; ii) the effect of aging on $\dot{V}_{\mathrm{O}_{2} \max }$ of smokers and non-smokers; and iii) standard "norms" of maximal oxygen uptake capacity of normal sedentary Indians of the age range $20-59$ years.

\section{METHODS}

Subjects. Eighty-four male smokers and 92 male non-smokers varying in age from 20 to 59 years were drawn at random from the student population and employees of Calcutta University. The subjects were healthy with no history of heart and lung diseases. They had no athletic training and were not involved in any strenuous physical conditioning programme except some recreational sports. The smokers and non-smokers were defined according to the criteria followed by MoRRIs et al. (1971). Pack year was calculated from number of packets of cigarettes smoked per day and total years of smoking.

Mean and standard deviation of physical characteristics of smokers and nonsmokers of different age groups are listed in Table 1 including smoking characteristics of smokers. The mean age, height, weight, and body surface area (BSA, $\mathrm{m}^{2}$ ) of smokers and non-smokers were almost similar. Only the mean body height of nonsmokers was found to be significantly higher then that of smokers $(p<0.05)$ in the 30-39-year age group. 


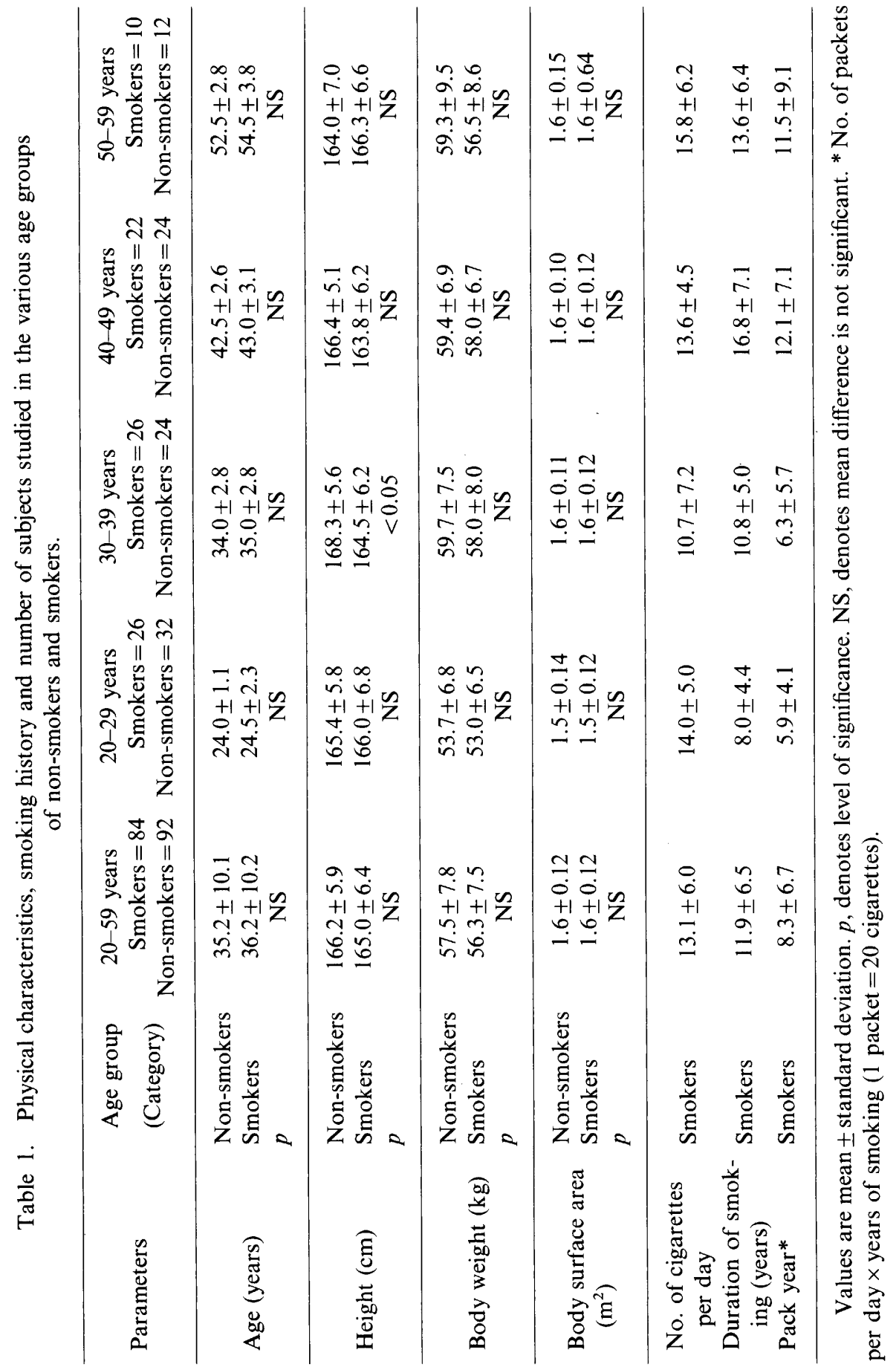


Preparation of subjects. The smokers were asked not to smoke at least $2 \mathrm{~h}$ prior to the test to exclude acute effect of smoking on airways. The tests on all the subjects were performed 2 to $3 \mathrm{~h}$ after a meal. Each subject refrained from energetic physical activity for $2 \mathrm{~h}$. preceding his work test. The laboratory temperatures ranged between $27-29^{\circ} \mathrm{C}$.

Exercise test. Before the exercise test, the details of the procedure were explained to the subjects to allay apprehension. At the beginning of the test, each subject's age (in years), standing height (in $\mathrm{cm}$ ), weight (in $\mathrm{kg}$ ), and smoking history were recorded. After the initial rest of half an hour, radial pulse rate was counted. BSA $\left(\mathrm{m}^{2}\right)$ of the subjects was calculated from the formula of DU BoIs and Du BoIs (1916).

The exercise was performed on a magnetic friction-type bicycle ergometer (model of Prof. E. A. Müller, Max-Planck Institute for Work Physiology). A lowresistance, high velocity, Collins "Triple-J"-type plastic valve was used for the collection of expired air by the open circuit method.

A preliminary warming up for $5 \mathrm{~min}$ at a rate of $600 \mathrm{~kg} \cdot \mathrm{m} \cdot \mathrm{min}^{-1}$ was given to each subject before the application of a set workload which was fixed at $720 \mathrm{~kg} \cdot \mathrm{m}$. $\min ^{-1}$. The work thereafter was increased by $120 \mathrm{~kg} \cdot \mathrm{m} \cdot \mathrm{min}^{-1}$ every $3 \mathrm{~min}$ until the subjects gave the indication of complete exhaustion and their heart rate went above 180 beats $\cdot \min ^{-1}$, which was the criterion of maximality (ÅsTRAND and RoDAHL, 1970). The workload was considered to be maximum when further increase of workload did not bring about any significant increase in oxygen uptake or the uptake was less than $100 \mathrm{ml} \cdot \mathrm{min}^{-1}$ in response to the next higher load. This was the "levelling off" method for determination of $\dot{V}_{\mathrm{O}_{2} \text { max }}$. Subjects in no case endured more than $10 \mathrm{~min}$ in this procedure of a continuously increasing workload.

Gas analysis and maximal pulmonary ventilation $\left(\dot{V}_{\mathrm{E} \max }\right)$. Analysis of gas, measurement of maximal pulmonary ventilation and maximal heart rate $\left(\mathrm{HR}_{\max }\right)$ were made by the method described by ChatterJee and CHAKRABOrTy (1986).

The experiments were performed at a room temperature varying from $27-29^{\circ} \mathrm{C}$ with the relative humidity varying between $60-70 \%$.

Statistical analysis. Statistical analysis used was the analysis of variance (ANOVA), correlation coefficient, and regression equation between two groups.

\section{RESULTS}

Smoking characteristics of smokers of various age groups are given in Table 1. The smokers of $20-59$ years of age smoked an average of $8.3 \pm 6.7$ pack years. They smoked an average of $13.1 \pm 6.0$ cigarettes per day for an average period of $11.9 \pm 6.5$ years.

Mean and standard deviations of maximum oxygen uptake capacity and its related parameters and comparison of these parameters between smokers and nonsmokers at their level of significance are listed in Table 2. Maximum oxygen uptake per $\mathrm{kg}$ of body weight $\left(\dot{V}_{\mathrm{O}_{2} \text { max }} / \mathrm{BW}\right)$ of smokers $20-59$ years old was found to be 


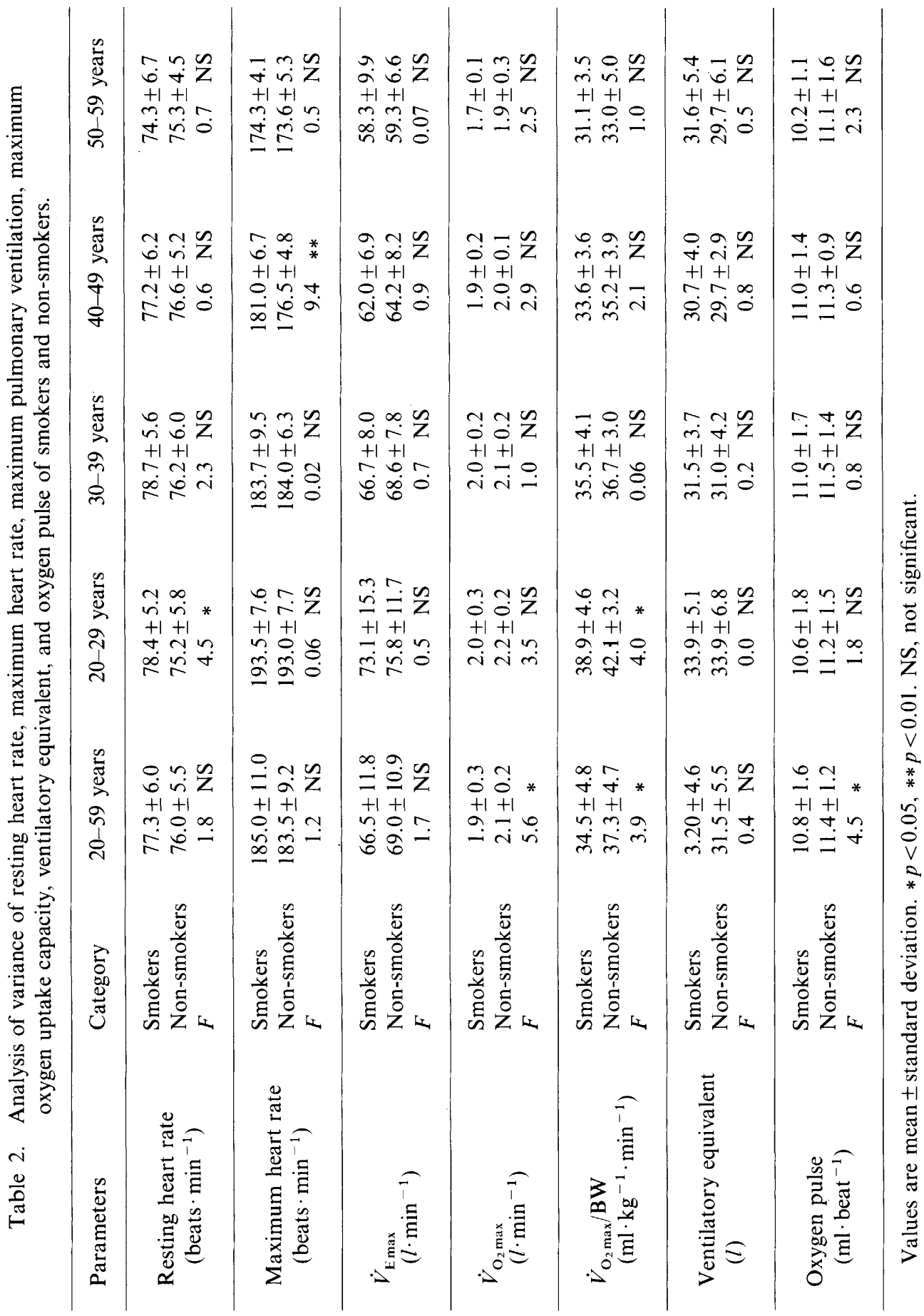

Vol. 37, No. 5, 1987 
significantly lower than that of non-smokers $(p<0.05)$. The smokers and nonsmokers of this age group were grouped in the decades. When the $\dot{V}_{\mathrm{O}_{2} \max } / \mathrm{BW}$ of smokers was compared with their non-smokers' counterpart of the corresponding age group, lower values were noted among the smokers. Difference in $\dot{V}_{\mathrm{O}_{2} \text { max }} / \mathrm{BW}$ between smokers and non-smokers became significant only in the 20-29-year-old group $(p<0.05)$. In other age groups, non-smokers predominated over smokers in $\dot{V}_{\mathrm{O}_{2} \max } / \mathrm{BW}$ but the differences were not statistically significant. $\dot{V}_{\mathrm{O}_{2} \max }$ of smokers (all ages combined) was found to be significantly lower. The statistical significance was not obtained when it was compared between the smokers and non-smokers of each age decade although the higher values were obtained in non-smokers.

The correlations of $\dot{V}_{\mathrm{O}_{2} \text { max }} / \mathrm{BW}$ obtained with pack years, number of cigarettes smoked per day, and number of years during which they smoked were -0.36 , -0.38 , and -0.42 , respectively, in the smokers of the 20-29-year-old age group. All these correlations were significant at the level of $1 \%$. In other age groups, all the correlations of smoking histories with $\dot{V}_{\mathrm{O}_{2} \max }$ were too small and were statistically insignificant.

From Table 2 it is clear that maximum oxygen uptake gradually decreased with increase in age both in smokers and non-smokers. Significant negative correlations of $\dot{V}_{\mathrm{O}_{2} \text { max }} / \mathrm{BW}$ with age and $\mathrm{BSA},-0.52$ and -0.49 , respectively, in non-smokers and -0.56 and -0.34 , respectively, in smokers, were obtained. Positive correlations of $\dot{V}_{\mathrm{O}_{2} \text { max }} / \mathrm{BW}$ with maximum heart rate $(0.52$ in non-smokers and 0.60 in smokers), maximum pulmonary ventilation ( 0.36 in non-smokers and 0.56 in smokers), and oxygen pulse ( 0.33 in non-smokers and 0.34 in smokers) were obtained. All the correlations were statistically significant. Maximum pulmonary ventilation $\left(\dot{V}_{\mathrm{E} \max }\right)$ did not differ significantly between non-smokers and smokers though the higher value was obtained in the former of all age groups. It was gradually decreased with the increase of age in both categories.

$\dot{V}_{\mathrm{E} \max }$ was found to be positively correlated with $\dot{V}_{\mathrm{O}_{2} \max }(0.38$ in non-smokers and 0.69 in smokers) and maximum heart rate (0.62 in non-smokers and 0.47 in smokers). It was negatively correlated with age $(-0.52$ in non-smokers and -0.47 in smokers). All the correlations were statistically significant.

Maximum heart rate $\left(\mathrm{HR}_{\max }\right)$ did not differ significantly between smokers and non-smokers except in the age group of $40-49$ years. $\mathrm{HR}_{\max }$ showed significant negative correlation with age and body weight of -0.73 and -0.22 , respectively, in non-smokers and of -0.70 and -0.23 , respectively, in smokers. Significant positive correlation was obtained with $\dot{V}_{\mathrm{E} \text { max }}, 0.62$ in non-smokers and 0.47 in smokers.

Resting heart rate was apparently higher in the smokers. The difference became significant only in the young age group.

Oxygen pulse was significantly higher in non-smokers of all ages combined (20-59 years), but the statistical significance of the difference disappeared when this value was compared to the individual age decades. Oxygen pulse remained almost unchanged with the advancing age. It was significantly and positively correlated with weight ( 0.55 in non-smokers and 0.66 in smokers), BSA (0.53 in non-smokers 


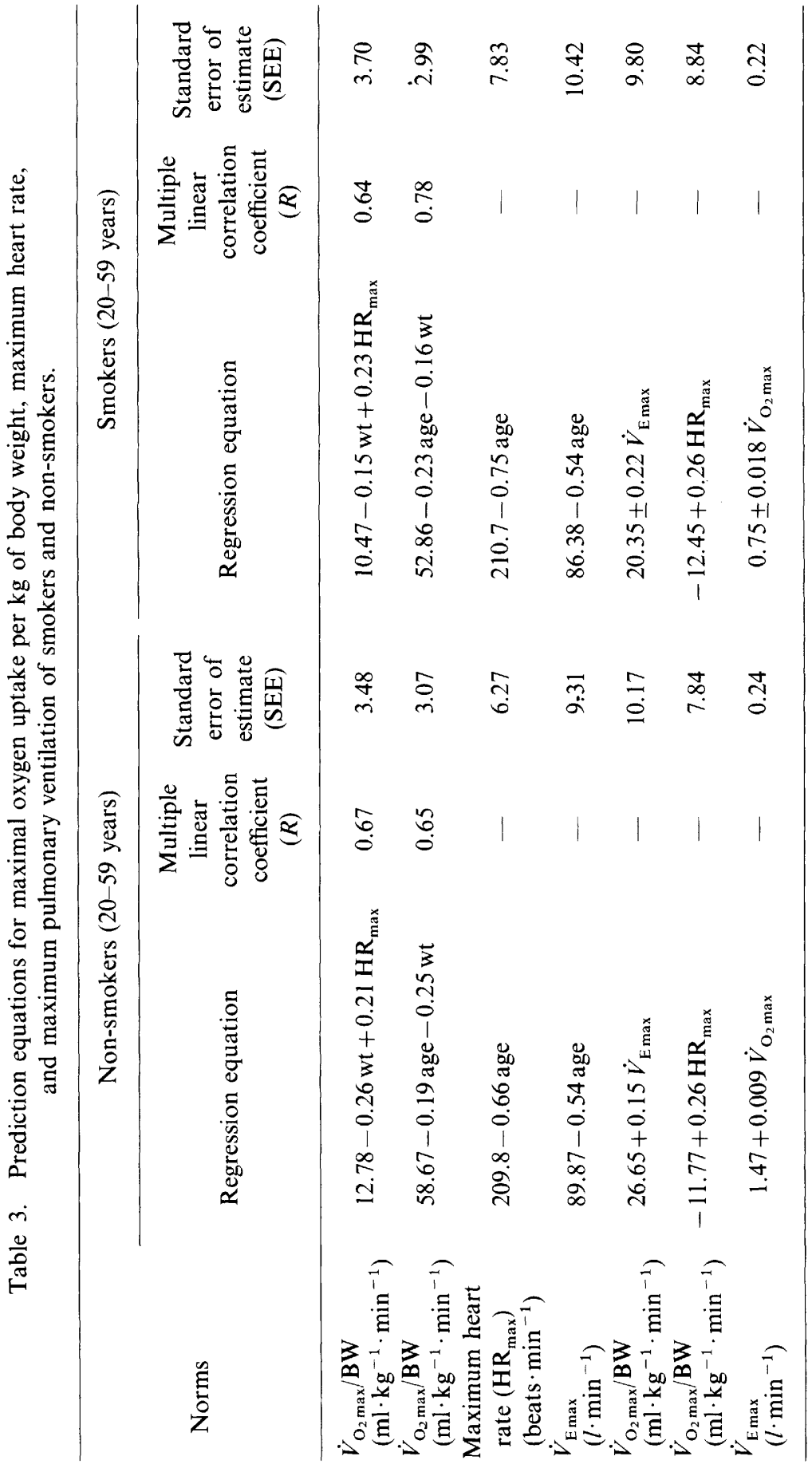

Vol. 37, No. 5, 1987 
and 0.65 in smokers), and $\dot{V}_{\mathrm{O}_{2} \max }$ (0.92 in non-smokers and 0.89 in smokers).

Ventilatory equivalent did not show any difference between the two categories.

Table 3 shows different prediction equations derived from one or more independent variables depending on the significant correlation with dependent variables.

\section{DISCUSSION}

The present study is based on two very similar groups of people. The general physical characteristics as well as environmental factors are comparable. Nevertheless, there were some marked difference in the results in the two groups of smokers and non-smokers.

Significant difference in maximum oxygen uptake between smokers and nonsmokers of 20-59 years age was readily apparent. But when the subjects of both categories were grouped into several age decades, this difference persisted only in the young age group. In other age groups, non-smokers predominated over smokers in $\dot{V}_{\mathrm{O}_{2} \text { max }} / \mathrm{BW}$ though the differences were not statistically significant. It is presumed that difference of $\dot{V}_{\mathrm{O}_{2} \text { max }}$ between smokers and non-smokers of age group 20-59 years became significant mainly because of the difference obtained in the young age group (20-29 years). The smokers and non-smokers were similar in age, height, body weight, physical activity, and dietary habit. Factors that might temporarily affect $\dot{V}_{\mathrm{O}_{2} \max }$ were minimized to the extent possible by the precaution observed. In the young age group, the $\dot{V}_{\mathrm{O}_{2} \max }$ of smokers was negatively and significantly correlated with pack year, number of cigarettes smoked per day, and the number of years during which they smoked.

The absence of significant differences in the $\dot{V}_{\mathrm{E} \max }$ and maximum heart rate and ventilatory equivalent of the non-smokers and smokers suggests that the lower $\dot{V}_{\mathrm{O}_{2} \max }$ of smokers might be due to smaller stroke volume and/or a poor oxygen extraction from blood. The significantly lower oxygen pulse at $\dot{V}_{\mathrm{O}_{2} \max }$ illustrates this. The smokers, therefore, had either a decreased stroke volume or decreased arteriovenous oxygen difference.

Another probable reason for the poor $\dot{V}_{\mathrm{O}_{2} \max }$ in smokers is suggested by increased terminal airway obstruction. A decrease in terminal air flow rates due to narrowing of peripheral airways has been reported in smokers (WALTER et al., 1979). Peripheral airway obstruction is known to cause ventilation perfusion imbalance and abnormalities in the gas exchange resulting in arterial desaturation (ANTHONISEN et al., 1968).

Also, greater alveolar-arterial $P_{\mathrm{O}_{2}}$ differences (STREIDER and KAZEMI, 1967; MCFADDEN and LINDEN, 1972) and lower diffusion capacities (MARTT, 1963; Krumholz et al., 1964) of smokers lead to arterial desaturation and hence decreased arteriovenous oxygen differences. Since the increase in $\dot{V}_{\mathrm{O}_{2}}$ at maximal workload occur mainly by increased $\mathrm{O}_{2}$ extraction from the blood, an existing arterial desaturation in smokers would set a limit to their $\dot{V}_{\mathrm{O}_{2} \max }$. 
Yet another factor that might contribute to the lower $\dot{V}_{\mathrm{O}_{2} \max }$ in these subjects is the chronically elevated carboxyhemoglobin ( $\mathrm{HbCO}$ ) level that is known to exist in the blood of smokers (CHEvalier et al., 1966). Smokers generally have HbCO values around $4-7 \%$ (Horvath et al., 1975). HbCO levels of 5-10\% were said to be commonly found in heavy smokers (BRODY and COBURN, 1969; KLAUSEN et al., 1968). MotLey (1971) reported average $\mathrm{HbCO}$ level of $5.67 \%$ in smokers (of $1-3$ packs/day). HoRvath et al. (1975) also reported that $\dot{V}_{\mathrm{O}_{2} \max }$ is not altered until $\mathrm{HbCO}$ levels exceed $4.3 \%$ and a linear decrease in $\dot{V}_{\mathrm{O}_{2} \max }$ occurs with increased levels of $\mathrm{HbCO}$. The smokers of the young age group of the present study had smoked 14 cigarettes per day (average) for 8 years (average) and fell under the category of heavy smokers. Their blood levels of $\mathrm{HbCO}$ were expected to be more than $4 \%$.

Interestingly, the $\dot{V}_{\mathrm{O}_{2} \text { max }}$ of smokers of other age groups was not significantly different from that of non-smokers. Also, the correlation of $\dot{V}_{\mathrm{O}_{2} \max }$ with smoking variables was very small and when this was corrected for age by partial correlation, the observed correlation became totally insignificant. The reason for such findings in these smokers is not yet clear. Though the smokers of 30-39, 40-49, and 50-59 years consumed many more cigarettes (in terms of pack years) than the young age group, we did not observe its deleterious effect on $\dot{V}_{\mathrm{O}_{2} \max }$. It suggests that there exists some mechanism that adapts the deleterious effect of smoking in these age groups, which is not yet known to us.

Aging diminishes maximum oxygen uptake capacity by decreasing maximal cardiac output and this effect seems to be partly due to decreased maximal heart rate (ÅsTRAND et al., 1959; HANSEN et al., 1968). In the present study, decrease in the $\dot{V}_{\mathrm{O}_{2} \max }$ with increasing age was found in both categories. RoBINSON (1938) and ÅstRAND (1952) found a decrease in $\dot{V}_{\mathrm{O}_{2} \max }$ from 3.53 to $2.63 \mathrm{l} \cdot \mathrm{min}^{-1}(25 \%)$ for non-smoker males from 25 to 50 years of age and 3.01 to $2.23 \mathrm{l} \cdot \mathrm{min}^{-1}(26 \%$ ) from about 35 to 63 years of age, respectively. Interestingly, in the present study $\dot{V}_{\mathrm{O}_{2} \max }$ of non-smokers decreased by $13 \%$ from 20 to 59 years whereas in smokers it was a little higher $(15.5 \%$ ) from 20 to 59 years of age. Figure 1 explains the relationship of age with $\dot{V}_{\mathrm{O}_{2} \text { max }} / \mathrm{BW}$. With the increase in age $\dot{V}_{\mathrm{O}_{2} \max }$ diminishes, the rate of deterioration being a little higher in smokers. Maximum oxygen uptake has an identical relationship with maximum heart rate (Fig. 2). Maximum pulmonary ventilation was decreased with the increase in age (Fig. 4) in both the categories, though the absolute value was slightly higher in non-smokers and rate of deterioration was similar in both the cases. The volume of pulmonary ventilation primarily depends upon the absolute workload. The maximal $\dot{V}_{\mathrm{O}_{2}}$ and $\dot{V}_{\mathrm{E}}$ decrease with age both in smokers and non-smokers. The decrease in total ventilation with aging hence evidently follows the decrease in $\dot{V}_{\mathrm{O}_{2}}$. The gradual decrease in $\dot{V}_{\mathrm{E} \max }$ with increasing age reflects gradual loss of capacity to expand the thoracic cage. Aging is known to decrease vital capacities and maximum breathing capacities and terminal expiratory flow rates (MARTT, 1963; MOTLEY, 1971; WALTER et al., 1979). These aging-induced alterations in ventilatory mechanics hinder the "bellow"s 

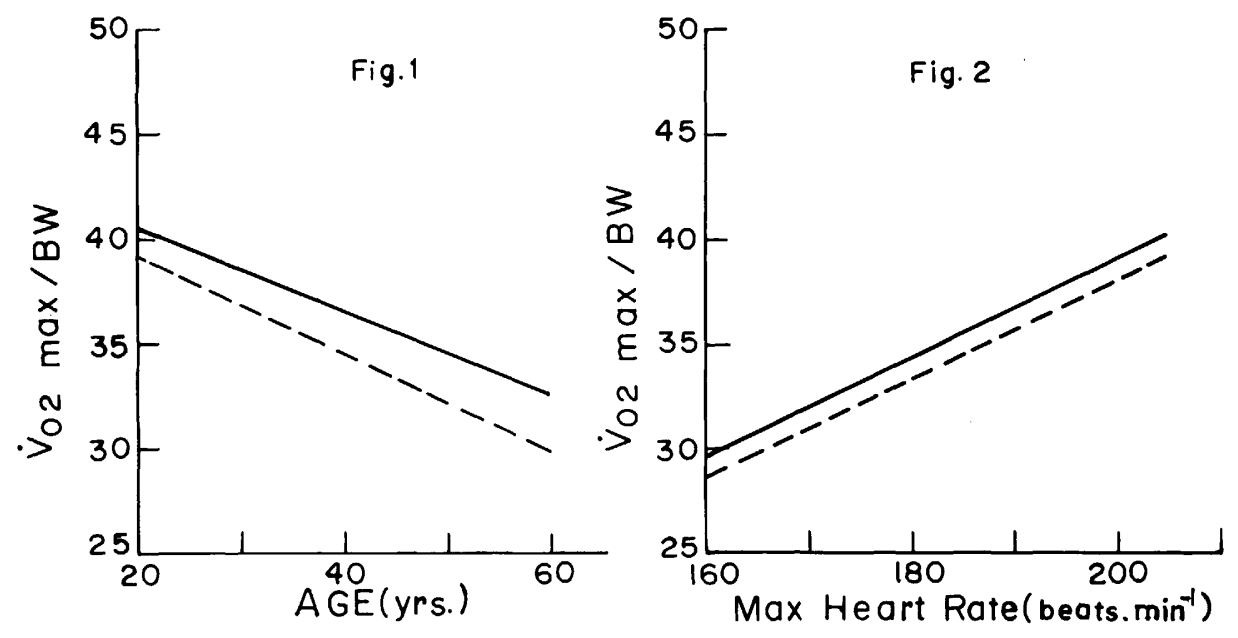

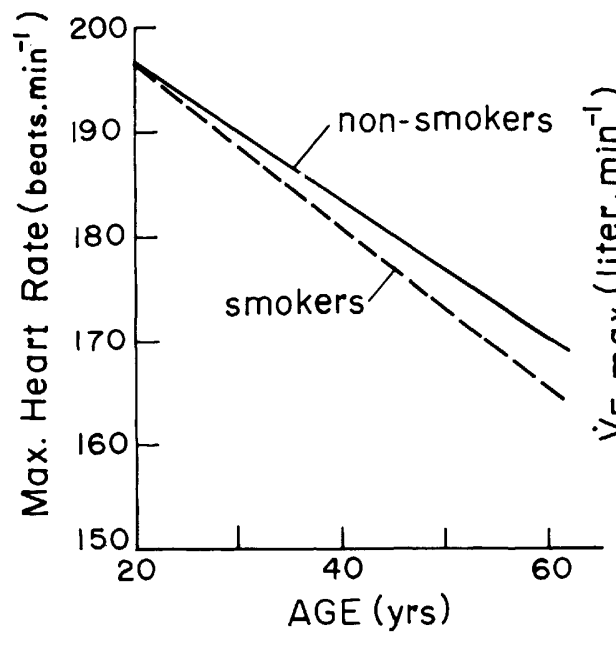

Fig. 3

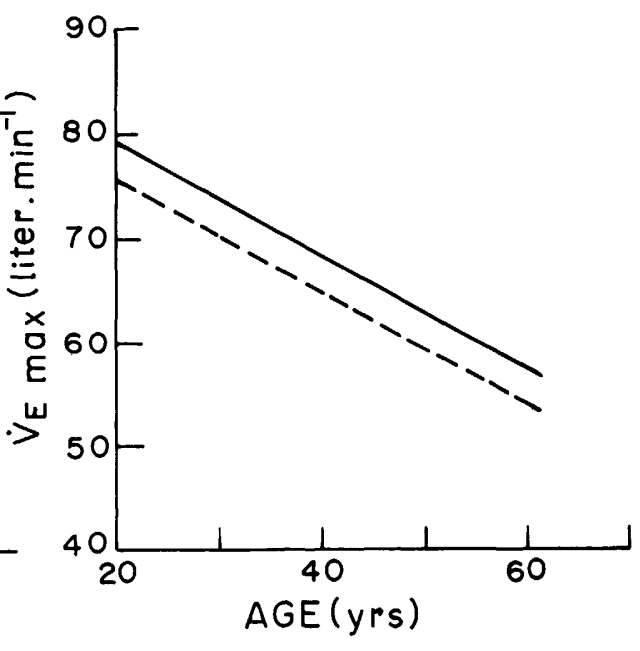

Fig. 4

Figs. 1-4. Regression lines of $\dot{V}_{\mathrm{O}_{2} \max }$ BW (Fig. 1), maximum heart rate (Fig. 3), $\dot{V}_{\mathrm{E} \max }$ (Fig. 4) on age; and $\dot{V}_{\mathrm{O}_{2} \text { max }} / \mathrm{BW}$ (Fig. 2) on maximum heart rate of smokers and non-smokers.

action of lung and hence lower maximal pulmonary ventilation.

Regarding $\dot{V}_{\mathrm{O}_{2} \max }$ some contradictory results are available. When WALTER and NANCY (1983) compared 4 active young heavy smokers with 5 active young nonsmokers, decreased $\dot{V}_{\mathrm{O}_{2} \max }$ was observed in the former. They failed to obtain such difference in the sedentary group of 7 young non-smokers and 6 young heavy smokers. Chevalier et al. (1963) also failed to obtain any significant differences in maximum oxygen uptake capacity between 18 young smokers and 14 young non- 
smokers. COOPER et al. (1968) reported similar results based on the study on 25 active young non-smokers and 22 active young smokers by maximal treadmill exercise. INGEMANN-HANSEN and HALKJAER-KRISTENSEN (1977) studied the $\dot{V}_{\mathrm{O}_{2} \max }$ in 17 moderate and 17 heavy smokers (young) in relation to 27 young non-smokers and reported a decrease in $\dot{V}_{\mathrm{O}_{2} \max }$ only in heavy smokers. When the $\dot{V}_{\mathrm{O}_{2} \max }$ was expressed relatively to lean body mass, the difference between non-smokers and moderate smokers also became significant.

The average values of $\dot{V}_{\mathrm{O}_{2} \text { max }}$ of young smokers and non-smokers obtained by COOPER et al. (1968) were much higher than those of comparable groups of the present study. Though the magnitude of difference in $\dot{V}_{\mathrm{O}_{2} \max } / \mathrm{BW}$ between smokers and non-smokers was similar in both the studies, the mean difference between these two categories became significant in the comparable age group of the present study. The higher values were likely due to difference in technique used, physical activity, and ethnic variation.

The results of the present investigation show a significant negative correlation $(r=-0.35, p<0.01)$ between $\dot{V}_{\mathrm{O}_{2} \max } / \mathrm{BW}$ and the daily cigarettes consumption. This is in agreement with the results of MCDONOUGH et al. (1970) and COOPER et al. (1968).

The mean $\dot{V}_{\mathrm{O}_{2} \max }$ of the sedentary Indian non-smokers as well as smokers is comparatively low indicating that they had lower aerobic capacity and poor standard of physical fitness in respect to Caucasian, Kurds, Yemenites, Europeans, and Africans (Wyndham et al., 1963; Davies et al., 1972). $\dot{V}_{\mathrm{O}_{2} \max }$ of Americans reported by COOPER et al. (1968), MCDONOUGH et al. (1970), RODE and SHEPHARD (1971), and Åstrand (1960), and of Danes reported by INGEMANN-HANSEN and HALKJAER-KRISTENSEN (1977) were much higher than that of Indians of comparable age groups, physical activity, and smoking characteristics.

The $\dot{V}_{\mathbf{O}_{2} \max }$ of active subjects reported by SEngupta et al. (1974), DAS (1968), BANERJEE et al. (1974), and WALTER and NANCY (1983) was much higher than that of the present study. The mean $\dot{V}_{\mathrm{O}_{2} \max }$ of the sedentary subjects of this study is similar to comparable group of Asians (DUNCAN, 1972). Lower $\dot{V}_{\mathrm{O}_{2} \max }$ among Indians in respect to others cannot be attributed to the difference in racial or ethnic origin. Whether true ethnic differences in work capacity exist is not known. However, DAviEs et al. (1972) studied men and women of four different ethnic groups and found no significant differences.

Resting heart rate was found to be significantly higher in smokers only in the young age group (20-29 years), while in other age groups no such differences were observed though the value was higher in smokers. Our observations are not in agreement with the findings of Blackburn and co-workers (BLACKBURN et al., 1960) who reported that in a group of young men there was no difference in heart rate between smokers and non-smokers at rest, during exercise, or $3 \mathrm{~min}$ after exercise. Our results confirmed the observations of CHEVALIER et al. (1963) who explained that the difference represented a physiologic difference in these two groups which was unrelated to smoking.

There was a gradual derease in maximum heart rate both in smokers and non- 
smokers with increase of age (Fig. 3). The rate of deterioration was slightly higher in smokers. The significant negative correlation was observed with age. Several investigators also found that the maximum heart rate decreased with age in normal subjects (RoBINSON et al., 1938; ÅsTRAND, 1952; ÅsTRAND et al., 1959; ÅsTRAND et al., 1964). ÅSTRAND (1960) reported a $9 \%$ decrease in maximum heart rate with age from 187 beats $\cdot \min ^{-1}$ in the youngest $\left(20-29\right.$ years) to 170 beats $\cdot \min ^{-1}$ in the oldest group (50-65 years). In the present study, maximum heart rate decreased by $10 \%$ from the youngest to the oldest age. Therefore, there is no doubt that young people can reach a higher heart rate level than older people, at least when performing such types of work as bicycling.

We did not observe any significant difference in maximum heart rate between smokers and non-smokers though there was a slightly higher maximal heart rate in smokers than that of non-smokers. But the $\mathrm{HR}_{\max }$ was found be significantly lower in non-smokers only in the age group 40-49 years. Reports have been made by several investigators (KARPOVICH and HALLE, 1951; COOPER et al., 1968; KRUMHOLZ and Hedrick, 1972; InGemann-Hansen and HalkJaer-Kristensen, 1977) on $\mathrm{HR}_{\max }$ of smokers and non-smokers. Among them some have reported that there was no difference in $\mathrm{HR}_{\max }$ between the groups (COOPER et al., 1968; INGEMANNHANSEN and HALKJAER-KRISTENSEN, 1977) while others have reported higher $\mathrm{HR}_{\max }$ in smokers in comparison to non-smokers (KRUMHOLZ and HEDRICK, 1972). Our observation of the significantly higher $\mathrm{HR}_{\max }$ in smokers (40-49 years) is similar to that reported by KRUMHOLZ and HEDRICK (1972).

Coefficients of determination $\left(R^{2}\right)$ and regression coefficients of the regression equations are statistically significant and the standard error of estimate did not vary widely. Hence these equations are found to be reproducible and reliable.

It is, therefore, concluded that the $\dot{V}_{\mathrm{O}_{2} \max }$ or aerobic capacity is an important determinant of the ability of an individual to carry on extended work and is the best indicator of physical fitness (MARTT, 1963; SHEPHARD et al., 1968). The present study showed that although the young smokers were asymptomatic, their physical fitness and their work capacity for prolonged muscular performance were impaired.

This study was supported by a grant from the Indian Council of Medical Research, New Delhi. The authors express sincere gratitude to Prof. S. Banerjee and Prof. S. R. Maitra for their constant encouragement and also wish to thank the subjects who participated in this study. The help of Mr. D. Das, Associate Professor of Physiology, Presidency College, Calcutta, in the statistical treatment of the data is gratefully acknowledged.

\section{REFERENCES}

Anthonisen, N. R., Bans, H., Oriol, A., Place, R. E. G., and Bates, D. V. (1968) Regional lung function in patients with chronic bronchitics. Clin. Sci., 35: 495.

Åstrand, I. (1960) Aerobic work capacity in men and women with special reference to age. Acta Physiol. Scand., 49 (Suppl. 169): 1-92.

Åstrand, I., Åstrand, P. O., and Rodahl, K. (1959) Maximal heart rate during work in 
older man. J. Appl. Physiol., 14: 562-566.

Åstrand, P. O. (1952) Experimental Studies of Physical Working Capacity in Relation to Sex and Age, Munksgaard, Copenhagen.

Åstrand, P. O., Cuddy, T. E., Saltin, B., and Stenberg, J. (1964) Cardiac output during submaximal and maximal work. J. Appl. Physiol., 19: 268.

Åstrand, P. O. and Rodahl, K. (1970) Text Book of Work Physiology, McGraw Hill Book Company, New York.

Banerjee, P. K., Chatterjee, S., Chatterjee, P., and Maitra, S. R. (1974) Aerobic capacity in Bengali young men trained and untrained. Indian J. Physiol. Allied Sci., 28(3): 91-99.

Blackburn, H., Brozek, J., Taylor, H. L., and Keys, A. (1960) Comparison of cardiovascular and related characteristics in habitual smokers and non-smokers. Ann. N. Y. Acad. Sci., 90: 277-289.

Brody, J. S. and Coburn, R. F. (1969) Carbonmonoxide induced arterial hypoxemia. Science, 164: 1297-1298.

Chatterjee, S. and Chakraborty, B. (1986) Comparative study of $\dot{V}_{\mathrm{O}_{2} \max }$ by three different ergometrics in untrained college women. Jpn. J. Physiol., 36: 151-162.

Chevalier, R. B., Bowers, J. A., Bondurant, S., and Ross, C. J. (1963) Circulatory and ventilatory effects of exercise in smokers and non-smokers. J. Appl. Physiol., 18(2): $357-360$.

Chevalier, R. B., Krumholz, R. A., and Ross, J. C. (1966) Reaction of non-smokers to carbonmonoxide inhalation, cardiopulmonary response at rest and during exercise. $J$. Am. Med. Assoc. (JAMA), 198: 1061-1064.

CoOper, K. H., Gay, G. O., and BotTenberG, R. A. (1968) Effect of cigarette smoking on endurance performance. J. Am. Med. Assoc. (JAMA), 203: 189-192.

DAs, S. K. (1968) The maximum aerobic capacity of the Gorkha soldiers. Indian J. Med. Res., 56: 1054-1062.

Davies, C. T. M., Barnes, C., Fox, R. H., Ojikutu, R. O., and Samueloff, A. S (1972) Ethnic differences in physical work capacity. J. Appl. Physiol., 33: 726-732.

Du Bors, D. and Du Bors, E. P. (1916) Clinical calorimetry. A formulae to estimate the approximate surface area if height and weight be known. Arch. Intern. Med., 17: 863871.

DunCAN, M. (1972) Aerobic work capacity in young untrained Asian men. Q. J. Exp. Physiol., 57: 247-256.

Hansen, J. S., Tabakin, B. S., and Levy, A. M. (1968) Comparative exercise cardiorespiratory performance of normal men in the third, fourth and fifth decade of life. Circulation, 37: 345 .

Horvath, S. M., Peter, P. R., Thomas, E. D., and David, J. G. (1975) Maximal aerobic capacity at different levels of carboxyhemoglobin. J. Appl. Physiol., 38: 300-303.

INGEMANN-HANSEN, T. and HALKJAER-KRISTENSEN, J. (1977) Cigarette smoking and maximal oxygen consumption rate in humans. Scand. J. Clin. Lab. Invest., 37: 143-148.

KarPovich, P. V. and HaLle, C. J. (1951) Tobacco smoking and physical performance. J. Appl. Physiol., 3: 616-621.

Klausen, K., Rasmussen, B., Guellerod, H., Madson, H., and Peterson, E. (1968) Circulation, metabolism and ventilation during prolonged exposure to carbon-monoxide and to high altitude. Scand. J. Clin. Lab. Invest., 22 (Suppl. 103): 26.

Krumholz, R. A., Chevalier, R. B., and Ross, J. C. (1964) Cardiopulmonary function in young smokers: A comparison of pulmonary function measurements and some car- 
diopulmonary response to exercise between a group of young smokers and a comparable group of non-smokers. Ann. Intern. Med., 60: 603-610.

Krumholz, R. A. and Hedrick, E. C. (1972) Exercise response of smoking and nonsmoking middle aged business executives. J. Lab. Clin. Med., 80: 79-87.

LARSEN, R. K. (1963) The chronic effects of cigarette smoking on pulmonary ventilation. Am. Rev. Respir. Dis., 88: 630-634.

MartT, J. M. (1963) Pulmonary diffusing capacity in cigarette smokers and nonsmokers. Ann. Intern. Med., 56: $39-46$.

McDonough, J. R., Kusumi, F., and Bruce, R. A. (1970) Variations in maximal oxygen intake with physical activity in middle aged men. Circulation, 41: 743--751.

MCFAdDEN, E. R. and Linden, D. A. (1972) A reducting in maximum midexpiratory flow rate. Am. J. Med., 52: 725 .

Morris, J. F., Koski, A., and JoHnson, L. C. (1971) Spirometric standards for healthy nonsmoking adults. Am. Rev. Respir. Dis., 103: 57-67.

MotLey, H. L. (1971) Environmental air pollution effect on pulmonary function. Aerosp. Med., 42: 1108-1110.

Robinson, S. (1938) Experimental studies of physical fitness in relation to age. Arbeitsphysiologie, 10: 251-323.

Rode, A. and Shephard, R. J. (1971) The influence of cigarette smoking upon the oxygen. Cost of breathing in near maximal exercise. Med. Sci. Sports, 3(2): 51-55.

Sengupta, J., Srinivasulu, N., Sampath Kumar, I., and Malhotra, M. S. (1974) Influence of age on maximal $\mathrm{O}_{2}$-uptake and maximal heart rate of Indians during work. Indian J. Med. Res., 62: 1228.

Shephard, R. J., Allen, C., Benade, A. J. S., Davies, C. T. M., Diprampero, P. E., Hedman, R., Mankiman, J. E., and Sim, R. (1968) The maximum oxygen intake: An international standard of cardiorespiratory fitness. Bull. W.H.O., 38: 757-764.

Streider, D. J. and Kazemi, H. (1967) Hypoxemia in young asymptomatic cigarette smokers. Ann. Thorac. Surg., 4: 523.

TAYLOR, H. L. (1959) Lung volume in smokers and non-smokers. Ann. Intern. Med., 51: 68-77.

Walter, S., Nancy, N. R., and Collic, C. R. (1979) Changes in forced expiratory spirogram in young male smokers. Am. Rev. Respir. Dis., 119: 717.

Walter, S. and NANCY, N. R. (1983) Maximal oxygen uptake in young Indian asymptomatic smokers and non-smokers. Indian J. Med. Res., 77: 133-143.

Wyndham, C. H., Straydom, N. B., Morrison, J. F., Peter, J., Williams, C. G., Bredell, C. A. G., and JOFFE, A. (1963) Difference between ethnic group in physical working capacity. J. Appl. Physiol., 18: 361-366. 